\title{
Paraplegia
}

\section{The Use of Bone-chip Grafts Fixed with Absorbable Bone Sealant (Absele*)}

\author{
B. Açikgöz, E. Özcan \\ Hacettepe University, School of Medicine, Department of Neurosurgery, 06100 \\ Hacettepe-Ankara, Turkey.
}

\begin{abstract}
Summary
In this study we have investigated the use of bone-chip grafts which were fixed by Absele. In the study 33 adult guinea-pigs were used. Bone grafts for cervical intervertebral fusions were carried out. At the end of the sixth week the bones were examined histopathologically. Both in the control fusion group and in the experiment group the bone grafts were found to be in good condition, but in the free graft group some bone fragments were found in muscle tissue. There was no evidence of foreign body reaction.
\end{abstract}

Key words: Bone grafts; Absele; Intervertebral bony fusion

Despite the use of small bone fragments for restoration of certain bone defects (Chalmers, 1959; Goldberg, 1972; Mowlem, 1944), in the skull base and in mobile places such as the intervertebral disc space, fixation may remain a problem. An absorbable material which has the ability to fix bone pieces together may solve this problem. On the other hand such material should not cause a host reaction response, nor infection. In this way Absele ${ }^{\star}$, an absorbable bone sealant, which is made of stabilised ox fibrin, solubulised ox collagen, dextran, glycerol and $\mathrm{H}_{2} \mathrm{O}$ (Harris, 1978) has been used. Up to date it was used both in animal and in clinical studies (Harris, 1978; Harris, 1980). The aim of this study is to investigate the use of bone fragments which are fixed by Absele in the repair of bone defects. In a preliminary study we implanted small bone fragments which were fixed by Absele into the muscle tissue of guinea-pigs (the grafts were taken from the femur of the same animal). Three weeks later examination of the bones revealed healthy bones without evidence of Absele and without any foreign body reaction. Then the experiment was planned and performed.

*Absele, Ethnor, Division of Ethicon, Ltd., Edinburgh, UK.

Correspondence to Dr B. Açikgöz, Hacettepe University, Institute of Neurological Sciences, 06100 Hacettepe-Ankara, Turkey. 


\section{Material and methods}

Thirty three adult guinea-pigs weighing between 250 to 300 grams were used. They were divided into three groups. The first group was the first surgical control group. The second was the control fusion group. After intraperitoneal Nembuthal anaesthesia $(25 \mathrm{mg} / \mathrm{Kg})$, under aseptic conditions midline skin incisions were made in the anterior cervical region. With the aid of an operation microscope, microsurgical dissection of the prevertebral muscles was carried out, the tracheal bundle was retracted medically, the carotid sheath laterally. The muscles were then divided by bipolar coagulation and the vertebral bodies and disc spaces in between were exposed. Using an air turbine burr, holes were made in the vertebral bodies. The discs were not entered. In the first control group the wounds were closed immediately. In the second group bone fragments were placed into the burr holes as free grafts. In the experiment group the bone grafts were retained in position by Absele. At the end of the sixth week the bones were removed as a block and after decalcification they were examined histopathologically.

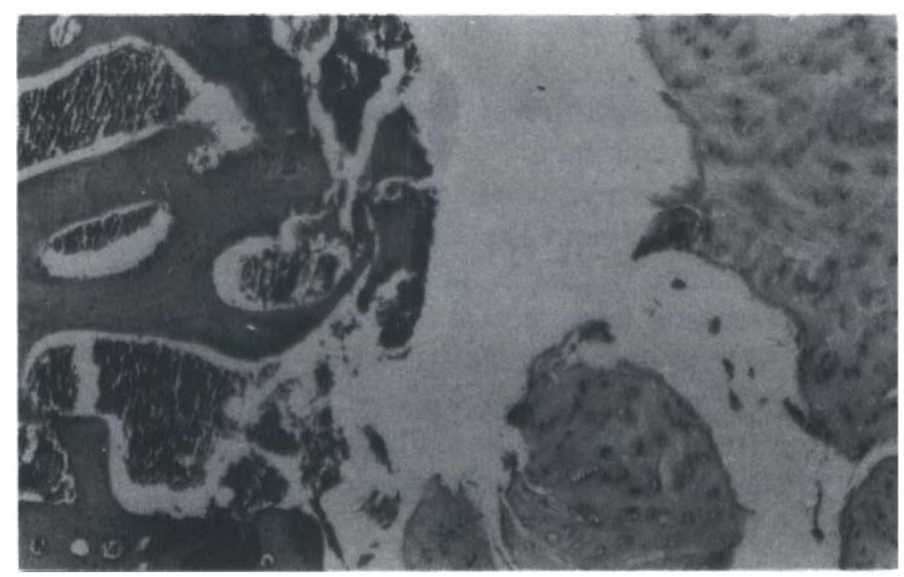

Figure 1 Bony cavity in control group. Vertebral body and disc tissue can be seen, H.E. $\times 100$.

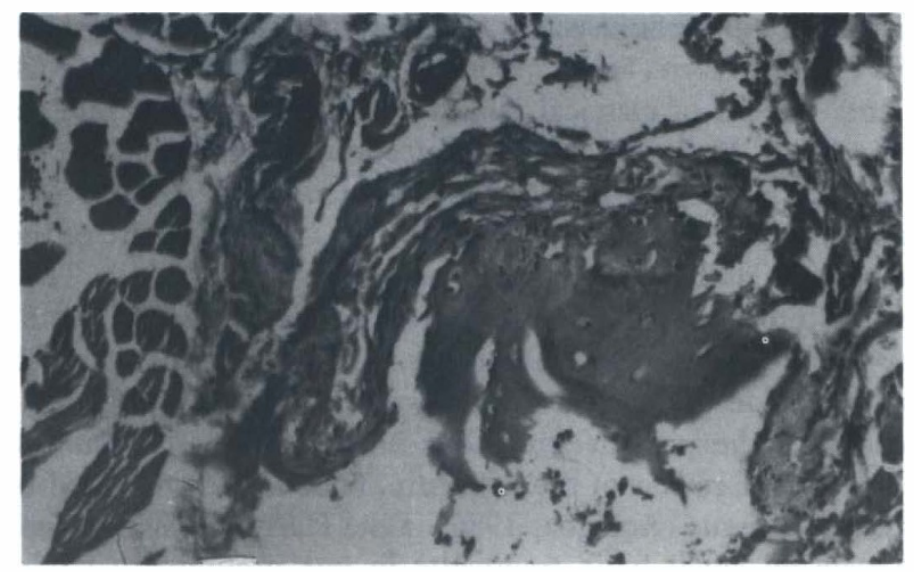

Figure 2 Control surgical group. Bony graft was seen in between muscle tissue, H.E. $\times 100$. 


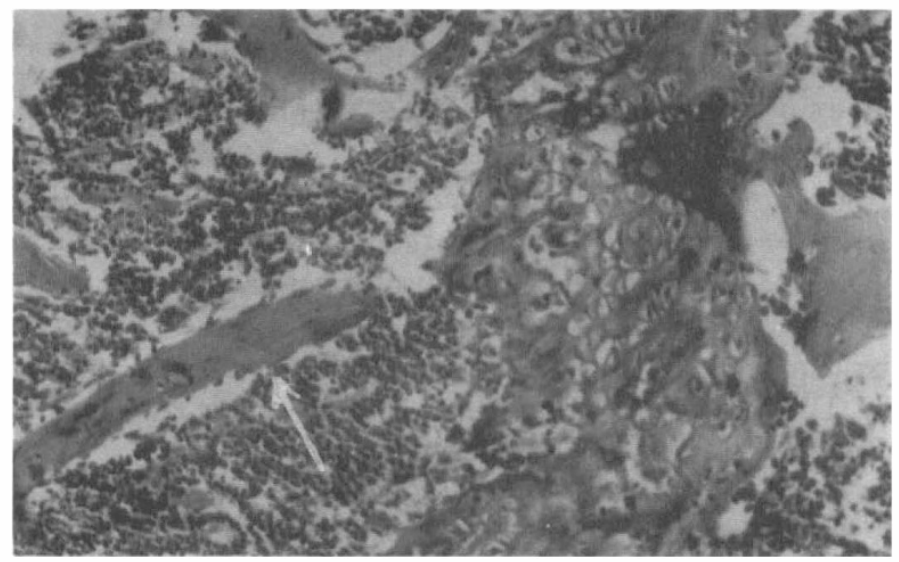

Figure 3 Experımental group, bony grafts in the cavity can be seen, H.E. $\times 100$.

\section{Resuíts}

Except in one animal that died during the surgical operation in the first control group, all animals were examined.

The examination of the vertebral bony cavities in the first control group revealed vital bony and disc tissue without the evidence of new bone formation (Fig 1).

Examination of the bone tissues in the second control group revealed healthy bone grafts. An interesting microscopial finding was the presence of some bone fragments (grafts) in the muscle tissue (Fig 2).

In the experiment group the cavities were found to be filled with healthy bone tissue. The bone grafts in the cavities were filled with osteocytes (Fig 3). There was no evidence of foreign body reaction nor of infection in any of the groups of animals.

\section{Discussion}

Absele is an absorbable bone sealant which was manufactured in 1977 (Harris, 1980). It was used by Harris and Capperauld $(1978,1980)$ experimentally and then in 259 patients instead of classical bone-wax. Their infection rate was found as $4 \cdot 6 \%$ (Harris, 1980). In the cases where infection was sustained the cultures were found as negative (Harris, 1980). Absele spontaneously absorb in 3 weeks (Harris, 1978; Harris 1980). We have chosen Absele in this study because of the properties of absorbance, availability, and ease of use.

This present study shows that the vertebral bodies of guinea-pigs can supply sufficient bone tissue for experimental studies. Although the vertebral bodies were located beneath the deep muscular layer they can be reached safely by a microsurgical approach. In the present study one animal was lost during surgery.

As is known from a review of the literature, bone fragments could be preserved in between muscle tissue (Açikgöz, 1986). Like Harris (1980) we first tested the effect of Absele on small bone fragments in our preliminary study.

Reconstruction studies of the skull base with alloplastic materials resulted in 
some cases in disaster because of inflammation and dislocation of the material (Wolfe, 1981).

In our second group dislocation of the free bone grafts remained as a technical difficulty. In this group in order to prevent the dislocation of bone fragments we sutured the muscle tissues carefully. But this technique was also insufficient. We avoided the usage of bone-wax for the closure of the burr holes.

Shehadi used a mixture of bone dust and $09 \% \mathrm{NaCl}$ in the reconstruction of skull defects (Shehadi, 1970). This was successful for defects up to $12 \mathrm{~cm}$ square. The main disadvantage of this method is the inability to obtain the shape of the defect. In the present study the shape can be obtained easily.

This study showed that in guinea-pig vertebrae bone grafts can with Absele be implanted. The Absele is subsequently absorbed.

In conclusion, we can state that a mixture of small bone fragments along with Absele can be used for the restoration of the skull base sellar floor after transphenoidal surgery. If stabilization can be achieved this mixture can also be employed for intervertebral bony fusions.

\section{Acknowledgements}

We are grateful to Dr Beyhan Demirhan for her kind help in the preparation of the pathology slides.

\section{References}

AÇıggöz B, Özcan OE, Erbengi A, Bertan V, Ruacan Ş, AÇı́göz HG 1986 Histopathologic and microdensitometric analysis of craniotomy bone flaps preserved between abdominal fat and muscle. Surgical Neurlogy 26:557-561.

Chalmers J, Sissons HA 1959 An experimental comparison of bone-grafting materials in the dog. Fournal of Bone and Foint Surgery 41B:209.

GOLDBERG VM, LANCE EM 1972 Revascularization and accreation in transplantation. Fournal of Bone and Foint Surgery 54A:807-816.

HARRIS P, CAPPERAULD I 1978 A new absorbable haemostatic bone sealant. Fournal of the Royal College of Surgeons of Edinburgh 23:285-291.

Harris P, CAPperauld I 1980 Clinical experience in neurosurgery with Absele, A new absorbable haemostatic bone sealant. Surgical Neurology 13:231-235.

MOWLEM R 1944 Cancellous chip bone-grafts. Reports on 75 cases. Lancet ii:746-748.

SHEHADI SI 1970 Skull reconstruction with bone dust. British fournal Plastic Surgery 23:227-234.

WoLfE SA 1981 Correction of a lower eyelid deformity caused by multiple extrusions of alloplastic orbital floor implants. Plastics and Reconstructive Surgery 68:429-432. 